\title{
KNOWLEDGE, ATTITUDES AND REPORTED PRACTICES REGARDING MANAGEMENT OF PATIENTS WITH BLEEDING DISORDERS AMONG ALEXANDRIA MINISTRY OF HEALTH DENTISTS A CROSS SECTIONAL ANALYTICAL STUDY
}

\begin{abstract}
Noha A. Elshafaei ${ }^{*} B D S$, Mona K. El Kashlan² $P h D$, Wafaa E. Abdelaziz² $P h D$
ABSTRACT

INTRODUCTION: Bleeding disorders and their complications are considered a significant health hazard worldwide. Research reports on the awareness of dental professionals regarding bleeding disorders were few and the researcher could not obtain any from Egypt.

OBJECTIVES: The objective of this study was to assess the knowledge, attitudes and reported practices of Ministry of Health (MOH) dentists regarding bleeding disorders and their management.

MATERIALS AND METHODS: This was an analytical, cross sectional study that was carried out in Alexandria during a period of 6 months from August 2018 to January 2019. The participants were asked to complete a comprehensive, close-ended self- administered questionnaire regarding patients with bleeding disorder. The questionnaire was previously pilot tested and validated by 4 professors at the Department of Pediatric Dentistry and Dental Public Health and 6 professors in the Department of Hematology, Faculty of Medicine-Alexandria University before releasing the final version of the questionnaire. It consisted of 33 items arranged in four sections. The first section was concerned with the demographic variables of the participating dentists. The second and third sections enquired about the participants' knowledge and attitudes regarding bleeding disorders symptoms and management, while the forth section of the questionnaire assessed the respondents' reported practices concerning bleeding disorders patients and actions taken to manage patients with the disease.

RESULTS: Dentists participating in the study ( $n=340$ from 400 with a response rate of $85 \%$ ) showed that Ministry of Health dentists had a fair knowledge, good attitudes and excellent reported practices toward bleeding disorders patients visiting the Ministry of Health clinics.

CONCLUSIONS: The present study showed a need to increase awareness of dental practitioners regarding bleeding disorders. Therefore, designing appropriate training programs for oral health care providers in order to enhance their practices towards the diagnosis and management of patients with bleeding disorders is mandatory.

KEYWORDS: Bleeding disorders, knowledge, attitudes, practice, dentists, Ministry of Health, Egypt.
\end{abstract}

1- Bachelor of Dental medicine and surgery 2006, Faculty of Dentistry, Alexandria University, Egypt.

2- Professor of Dental Public health, Faculty of Dentistry, Alexandria University, Egypt.

*Corresponding author:

E-mail: noha.elshafaei @gmail.com

\section{INTRODUCTION}

Hematological disorders are those systemic conditions with malfunction in the production of blood and its components (blood cells and proteins) (1). They are generally classified into three groups: red blood cell (RBC) disorders, white blood cell (WBC) disorders and bleeding disorders (2). The latter is a group of disorders that share the inability to form a proper blood clot (3). They are characterized by extended bleeding after injury, surgery, trauma or menstruation (3). Bleeding disorders may be congenital or acquired (3). They can be classified as coagulation factor deficiencies, platelet disorders, vascular disorders or fibrinolytic defects $(4,5)$.

Recognition of the signs and symptoms of bleeding disorders is an important aspect of dental management to provide an opportunity for the dentist to assist in the screening and monitoring of the underlying condition (4).

Management of bleeding disorders depends on the severity of the condition and the invasiveness of the planned dental procedure (1). It is, thus, mandatory to seek hematologist's advice prior to any dental treatment associated with an increased risk of bleeding (1).

Different studies were conducted to assess the knowledge, attitudes and practices of dental practitioners, regarding bleeding disorders, their complications and management.

Potdar et al (6), in Buraidah and Riyadh cities, Saudi Arabia, concluded that training is required to improve the poor knowledge and skills of dental students in management of patients with bleeding disorders.

George (7), assessed awareness of bleeding disorders among dental professionals in Chennai, India. The study concluded that a better assessment of past medical and dental history, better knowledge about bleeding disorders and its management can prevent the complications of many surgical and dental procedures.

In Egypt, no available data about the knowledge, attitudes and reported practices of dentists regarding management of patients with bleeding disorders could be retrieved. According to the Annual global Survey 2017, Egypt's total population was 97,553,151, with 5, 779 people suffering from hemophilia, 562 people with von Willebrand disease and 1,232 people with other bleeding disorders (8). Since adequate and safe prophylactic, restorative and surgical dental care of such patients is best accomplished by practitioners who are knowledgeable about the complications and treatment options associated with these conditions (8), thus, the present study aimed to investigate 
those variables among dentists working in the different Ministry of Health facilities, in Alexandria Governorate

\section{MATERIALS AND METHODS}

\section{Ethical consideration}

The approval of the Research Ethics Committee at the Faculty of Dentistry, Alexandria

University, was first obtained followed by a letter seeking approval of the Alexandria Directorate of Health Affairs in order to gain access to the Healthcare facilities. The permission of the participating dentists was also obtained through a detailed explanation of the objectives of the research, in order to gain their trust and confidence as well as their full cooperation. Returning back the filled questionnaire was considered as an implied consent with no need for further written consent according to the Helsinki declaration of research ethics 2013. (ID of the ethics committee is IORG0008839).

\section{Study design}

A cross sectional analytical study was conducted.

\section{Study setting}

Ministry of Health $(\mathrm{MOH})$, in Alexandria, is formed of eight health districts namely; Middle, West, East, El Gomrok, El Montazah, Borg El Arab, El Agamy and El Ameriya. In addition to the eight previous districts, there are facilities that are directly managed by the Directorate of Health Affairs, namely; Smouha center and MoharamBeik center.

\section{Study sample}

The total number of dentists working in the different health districts of Alexandria governorate (1866 dentists) was obtained from the directorate of health affairs. (Table 1).

Table (1): Study sample allocated from the different $\mathrm{MOH}$ facilities, in Alexandria.

\begin{tabular}{||c|c|c|c|}
\hline District & $\begin{array}{c}\text { Total number } \\
\text { of dentists } \\
\text { (N) }\end{array}$ & $\begin{array}{c}\text { Sample } \\
\text { size } \\
\text { (n) }\end{array}$ \\
\hline 1 & El Montazah & 273 & 47 \\
\hline 2 & East & 480 & 82 \\
\hline 3 & Middle & 265 & 46 \\
\hline 4 & West & 84 & 15 \\
\hline 5 & El Agamy & 44 & 8 \\
\hline 6 & El Gomrok & 100 & 17 \\
\hline 7 & Borg El Arab & 223 & 38 \\
\hline 8 & El Ameriyah & 133 & 23 \\
\hline 9 & $\begin{array}{c}\text { Smouha } \\
\text { Research Center }\end{array}$ & 149 & 36 \\
\hline 10 & $\begin{array}{c}\text { Meharam bek } \\
\text { center }\end{array}$ & 115 & 20 \\
\hline & Total & 1866 & 332 \\
\hline
\end{tabular}

A minimal sample size of 317 dentists was estimated by $G$ power softwareto be representative of the whole dentists' population. (9) Then, a proportional allocation sample was taken from each district to be representative of $\mathrm{MOH}$ dentists in Alexandria. The sample size was approximated to 332 after doing the proportional allocation (Table 1). The questionnaire was distributed among a sample of dentists from the different $\mathrm{MOH}$ settings until the predetermined sample size for each district was reached.

\section{Study tool}

The study tool was a comprehensive self-administered questionnaire, specially designed for the study and based on literature review $(1,4,10)$. It was pilot tested to ensure clarity and consistency of the questions.
Content validity index (11) of the questionnaire was executed through approaching 4 professors at the Department of Pediatric Dentistry and Dental Public Health and 6 professors in the Department of Hematology, Faculty of Medicine-Alexandria University, who reviewed the content validity of all four parts of the questionnaire and each gave statistical weight to the questions in all the four sections. For testing reliability of the questionnaire, the Cronbach's alpha coefficient test was used. For the 3 dimensions measured, namely: knowledge, attitudes and practices, the Cronbach's alpha values were 0.873 (Good reliability), 0.749 (acceptable reliability), 0.817 (acceptable reliability), respectively. These results indicate a satisfactory level of construct validity and internal consistency of the questionnaire

Data were collected in 6 months period from August to January 2018. The initiallyapproached sample consisted of 400 dentists, only 340 dentists agreed to complete thequestionnaire, giving a response rate of $85 \%$.

The questionnaire consisted of 33-items arranged in four sections: demographic data (8 questions), knowledge (15 questions), attitudes (7 statements) and reported practices (3 questions) regarding patients with bleeding disorders. The first section was concerned with the demographic and personal information of the participants such as age, gender, academic position (general practitioners/ specialists), average years of practice, and prior participation in any courses related to bleeding disorders and their management.

The second section was concerned with the participants' knowledge regarding bleeding disorders, specifically management in the dental clinic and oral manifestations related to these disorders.

The third section was related to dentists' attitudes toward the management of patients with bleeding disorders. The first question was asking the dentists if they feel that they have a role to diagnose and manage bleeding disorders in dental practice. The other six questions were about attitudes and beliefs toward bleeding disorders and their management from their education and knowledge.

The last section included three questions about the reported practices of the dentists while managing patients with bleeding disorders. They were asked if they had ever treated a patient with a bleeding disorder and how often they did. There was an enquiry about the line of action they follow if they suspect a bleeding disorder and finally, they were asked about their advice to bleeding disorder patients about the different preventive measures that can be used.

\section{Statistical analysis}

Data were collected and analyzed using SPSS (Statistical Package for Social Science) (ver 21) (IBM Corp. Released 2012. IBM SPSS Statistics for Windows, Version 21.0. Armonk, NY: IBM Corp.) The developed pie charts were constructed using Microsoft excel software). An alpha level was set to $5 \%$ with a significance level of $95 \%$, and a beta error accepted up to $20 \%$ with a power of study of $80 \%$ ( $\mathrm{p} \leq$ 0.05).

Data were entered as numerical or categorical, as appropriate. Data were described using minimum, maximum, mean and 95\% CI (Confidence Interval) of the mean (12), median and inter-quartile range.Categorical variables were described using frequency and percentage and the Chi-square test was used to test association between 
qualitative variables. (13) MonteCarlo correction (14) was carried out when indicated.

Content Validity Index (CVI) was used to test the degree to which the instrument has an appropriate sample of items for the construct being measured. (10) It was also used to test whether or not the items sampled for inclusion on the tool adequately represent the domain of content addressed by the instrument (15).

\section{Scoring system}

The Mean Score Percent was used as the scoring system for each question and for each section. This is because the four sections of personal data, knowledge, attitudes and practices contained different number of questions. Mean score percent $=($ Actual score $*(100 /$ Maximum score $))$

- For the fifteen questions of "knowledge about bleeding disorders", each correct answer was given a score of 1 while an incorrect answer was assigned a score of 0 . Individual scores were summed up to yield a total score that ranged from 0-15. This total score was then divided by the maximum score 15 to get the percent for each participant. Knowledge percentages were categorized into; poor (less than 25\%), fair (25\%-50\%), good (50\%-75\%) and excellent (more than 75\%).

- Each item of the seven statements of dentists' attitudes towards bleeding disorders was given either a score of 1 for each positive attitude or a score of zero for either a negative or a neutral attitude. These individual scores were then summed up and then divided by the maximum score 7 to get the percent for each participant. Attitudes percentages were also categorized into; poor (less than 25\%), fair (25\%-50\%), good (50\%-75\%) and excellent (more than 75\%).

- Dentists' reported practices related to bleeding disorders were evaluated from the second and third questions only. Each correct answer was given a score of one point and then summed up with the other correct items and then divided by the maximum score 2 to get the percent for each participant. Reported practices percentages were also categorized into; poor (less than 25\%), fair (25\%-50\%), good (50\%-75\%) and excellent (more than $75 \%$ ).

\section{RESULTS}

Demographic and practice related characteristics of the study participants are presented in Table (2). Table (3) A, $\mathbf{B}$ and $\mathbf{C}$ show the distribution of knowledge, attitudes and practice scores according to independent variables.
Table (2): Demographic and practice related characteristics of the study participants

\begin{tabular}{|c|c|c|c|}
\hline & Variables & $\mathbf{N}$ & $\%$ \\
\hline \multirow{4}{*}{$\begin{array}{l}\text { Age category } \\
\text { (years) }\end{array}$} & $20-<30$ & 95 & 27.94 \\
\hline & $30-<40$ & 191 & 56.18 \\
\hline & $40-<50$ & 28 & 8.24 \\
\hline & $50+$ & 26 & 7.65 \\
\hline \multirow[t]{2}{*}{ Gender } & Male & 37 & 10.88 \\
\hline & Female & 303 & 89.12 \\
\hline \multirow[t]{2}{*}{ Specialty } & $\begin{array}{r}\text { General } \\
\text { practitioner }\end{array}$ & 221 & 65 \\
\hline & Specialist & 119 & 35 \\
\hline \multirow{5}{*}{$\begin{array}{l}\text { Type of } \\
\text { specialty }\end{array}$} & Conservative & 17 & 14.29 \\
\hline & Oral surgery & 31 & 26.05 \\
\hline & Public health & 23 & 19.33 \\
\hline & Pedodontist & 27 & 22.69 \\
\hline & Other & 21 & 17.64 \\
\hline \multirow{4}{*}{$\begin{array}{l}\text { Average years } \\
\text { of experience }\end{array}$} & $1-<5$ & 75 & 22.06 \\
\hline & $5-<10$ & 77 & 22.65 \\
\hline & $10-<20$ & 155 & 45.59 \\
\hline & $20+$ & 33 & 9.71 \\
\hline \multirow{2}{*}{$\begin{array}{l}\text { Undergraduate } \\
\text { training }\end{array}$} & Yes & 72 & 21.18 \\
\hline & No & 268 & 78.82 \\
\hline \multirow{3}{*}{$\begin{array}{l}\text { Undergraduate } \\
\text { courses }\end{array}$} & Oral surgery & 47 & 66.20 \\
\hline & Oral medicine & 5 & 7.04 \\
\hline & Other & 19 & 26.76 \\
\hline \multirow{2}{*}{$\begin{array}{l}\text { Receiving } \\
\text { training courses }\end{array}$} & Yes & 103 & 30.29 \\
\hline & No & 237 & 69.71 \\
\hline \multirow{4}{*}{$\begin{array}{l}\text { Number of } \\
\text { training courses } \\
\text { received since } \\
\text { graduation }\end{array}$} & 1 & 40 & 38.83 \\
\hline & $2-3$ & 48 & 46.60 \\
\hline & $4-5$ & 11 & 10.68 \\
\hline & $>5$ & 4 & 3.88 \\
\hline \multirow{4}{*}{$\begin{array}{c}\text { The most recent } \\
\text { course }\end{array}$} & 0-6 months ago & 18 & 17.31 \\
\hline & A year ago & 13 & 12.50 \\
\hline & $1-2$ years ago & 23 & 22.12 \\
\hline & $>2$ years ago & 50 & 48.08 \\
\hline \multirow{2}{*}{$\begin{array}{rr}\text { Trying } \begin{array}{r}\text { Self- } \\
\text { learning }\end{array} \\
\end{array}$} & Yes & 235 & 69.12 \\
\hline & No & 105 & 30.88 \\
\hline \multirow{2}{*}{$\begin{array}{ll}\text { How } & \begin{array}{l}\text { did you } \\
\text { self-learn }\end{array} \\
\end{array}$} & Websites & 205 & 87.23 \\
\hline & Other & 30 & 12.77 \\
\hline
\end{tabular}

Almost $90 \%$ of the sample consisted of females and those who were less than 30 years of age accounted for $27.94 \%$. With regard to qualification, approximately two thirds of the participants were general practitioners having a bachelor's degree (65\%). Of the remaining one third who are specialists, nearly quarter of them are oral surgeons (26.05\%), followed by pedodontists (22.69\%) and dental public health dentists (19.33\%). 
Table (3A): Distribution of knowledge scores according to independent variables.

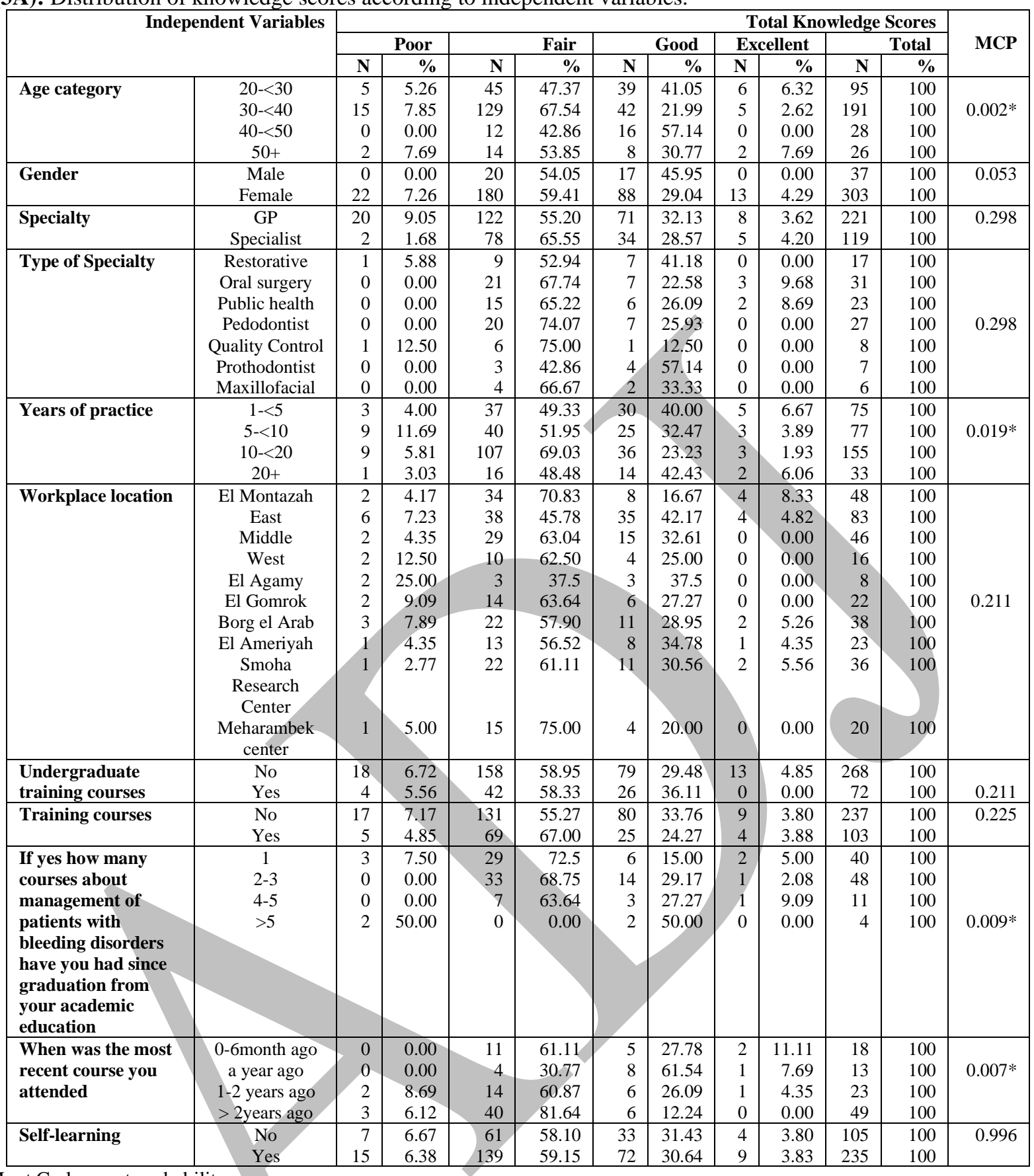

MCP: Mont Carlo exact probability

$* \mathrm{P}<0.05$ (significant) 
Table (3B): Distribution of attitudes scores according to independent variables.

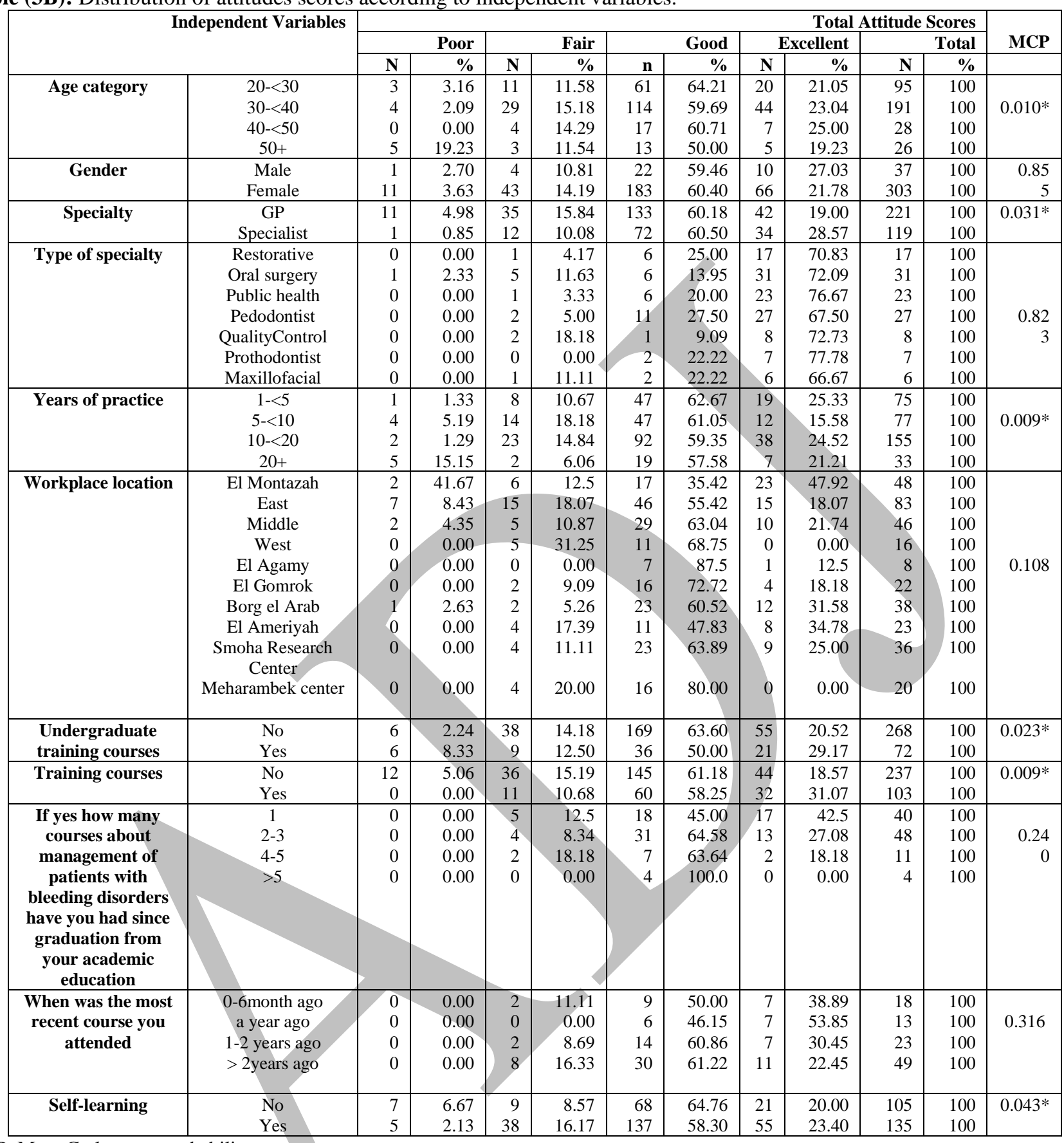

MCP: Mont Carlo exact probability

$* \mathrm{P}<0.05$ (significant) 
Table (3C): Distribution of practice scores according to independent variables.

\begin{tabular}{|c|c|c|c|c|c|c|c|c|c|c|c|c|}
\hline \multicolumn{2}{|c|}{ Independent Variables } & \multicolumn{10}{|c|}{ Total Practice Scores } & \multirow{3}{*}{ MCP } \\
\hline & & \multicolumn{2}{|r|}{ Poor } & \multicolumn{2}{|r|}{ Fair } & \multicolumn{2}{|r|}{ Good } & \multicolumn{2}{|c|}{ Excellent } & \multicolumn{2}{|r|}{ Total } & \\
\hline & & $\mathbf{N}$ & $\%$ & $\mathbf{N}$ & $\%$ & $\mathbf{n}$ & $\%$ & $\mathbf{n}$ & $\%$ & $\mathbf{N}$ & $\%$ & \\
\hline \multirow[t]{4}{*}{ Age category } & $20-<30$ & 12 & 12.64 & 55 & 57.89 & 0 & 0.00 & 28 & 29.47 & 95 & 100 & \multirow{4}{*}{0.124} \\
\hline & $30-<40$ & 24 & 12.57 & 80 & 41.88 & 0 & 0.00 & 87 & 45.55 & 191 & 100 & \\
\hline & $40-<50$ & 2 & 7.14 & 11 & 39.29 & 0 & 0.00 & 15 & 53.57 & 28 & 100 & \\
\hline & $50+$ & 4 & 15.38 & 10 & 38.46 & 0 & 0.00 & 12 & 46.16 & 26 & 100 & \\
\hline \multirow[t]{2}{*}{ Gender } & Male & 4 & 10.81 & 15 & 40.54 & 0 & 0.00 & 18 & 48.65 & 37 & 100 & \multirow[t]{2}{*}{0.653} \\
\hline & Female & 38 & 12.54 & 141 & 46.53 & 0 & 0.00 & 124 & 40.93 & 303 & 100 & \\
\hline \multirow[t]{2}{*}{ Specialty } & GP & 32 & 14.48 & 116 & 52.49 & 0 & 0.00 & 73 & 33.03 & 221 & 100 & \multirow[t]{2}{*}{$0.000^{*}$} \\
\hline & Specialist & 10 & 8.40 & 40 & 33.62 & 0 & 0.00 & 69 & 57.98 & 119 & 100 & \\
\hline \multirow[t]{7}{*}{ Type of speciality } & Restorative & 2 & 11.76 & 8 & 47.06 & 0 & 0.00 & 7 & 41.18 & 17 & 100 & \multirow{7}{*}{$0.004^{*}$} \\
\hline & Oral surgery & 6 & 19.35 & 13 & 41.94 & 0 & 0.00 & 12 & 38.71 & 31 & 100 & \\
\hline & Public health & 0 & 0.00 & 6 & 26.09 & 0 & 0.00 & 17 & 73.91 & 23 & 100 & \\
\hline & Pedodontist & 0 & 0.00 & 4 & 14.81 & 0 & 0.00 & 23 & 85.19 & 27 & 100 & \\
\hline & QualityControl & 2 & 25.00 & 2 & 25.00 & 0 & 0.00 & 4 & 50.00 & 8 & 100 & \\
\hline & Prothodontist & 0 & 0.00 & 2 & 28.57 & 0 & 0.00 & 5 & 71.43 & 7 & 100 & \\
\hline & Maxillofacial & 0 & 0.00 & 5 & 83.33 & 0 & 0.00 & 1 & 16.67 & 6 & 100 & \\
\hline \multirow[t]{4}{*}{ Years of practice } & $1-<5$ & 9 & 12.00 & 45 & 60.00 & 0 & 0.00 & 21 & 28.00 & 75 & 100 & \multirow{4}{*}{$0.018^{*}$} \\
\hline & $5-<10$ & 15 & 19.48 & 28 & 36.36 & 0 & 0.00 & 34 & 44.16 & 77 & 100 & \\
\hline & $10-<20$ & 14 & 9.03 & 72 & 46.45 & 0 & 0.00 & 69 & 44.52 & 155 & 100 & \\
\hline & $20+$ & 4 & 12.12 & 11 & 33.33 & 0 & 0.00 & 18 & 54.55 & 33 & 100 & \\
\hline \multirow{10}{*}{ Workplace location } & El Montazah & 7 & 14.58 & 28 & 58.34 & 0 & 0.00 & 13 & 27.08 & 48 & 100 & \multirow{10}{*}{$0.009 *$} \\
\hline & East & 41 & 49.40 & 14 & 16.87 & 0 & 0.00 & 28 & 33.73 & 83 & 100 & \\
\hline & Middle & 8 & 17.40 & 19 & 41.30 & 0 & 0.00 & 19 & 41.30 & 46 & 100 & \\
\hline & West & 0 & 0.00 & 10 & 62.5 & 0 & 0.00 & 6 & 37.5 & 16 & 100 & \\
\hline & El Agamy & 1 & 12.5 & 3 & 37.5 & 0 & 0.00 & 4 & 50.00 & 8 & 100 & \\
\hline & El Gomrok & 2 & 9.09 & 12 & 54.55 & 0 & 0.00 & 8 & 36.36 & 22 & 100 & \\
\hline & Borg el Arab & 5 & 13.15 & 10 & 26.32 & 0 & 0.00 & 23 & 60.53 & 38 & 100 & \\
\hline & El Ameriyah & 0 & 0.00 & 12 & 52.17 & 0 & 0.00 & 11 & 47.83 & 23 & 100 & \\
\hline & Smoha Research & 4 & 11.11 & 10 & 27.78 & 0 & 0.00 & 22 & 61.11 & 36 & 100 & \\
\hline & $\begin{array}{c}\text { Center } \\
\text { Meharambek } \\
\end{array}$ & 1 & 5.00 & 11 & 55.00 & 0 & 0.00 & 8 & 40.00 & 20 & 100 & \\
\hline Undergraduate & No & 31 & 11.57 & 119 & 44.40 & 0 & 0.00 & 118 & 44.03 & 268 & 100 & 0.253 \\
\hline training courses & Yes & 11 & 15.28 & 37 & 51.39 & 0 & 0.00 & 24 & 33.33 & 72 & 100 & \\
\hline Training courses & No & 36 & 15.19 & 116 & 48.95 & 0 & 0.00 & 85 & 35.86 & 237 & 100 & $0.002 *$ \\
\hline & Yes & 6 & 5.83 & 40 & 38.83 & 0 & 0.00 & 57 & 55.34 & 103 & 100 & \\
\hline $\begin{array}{l}\text { If yes how many } \\
\text { courses about }\end{array}$ & & 0 & 0.00 & 19 & 47.5 & 0 & 0.00 & 21 & 52.5 & 40 & 100 & \\
\hline $\begin{array}{c}\text { management of } \\
\text { patients with }\end{array}$ & & 6 & 12.5 & 13 & 27.08 & 0 & 0.00 & 29 & 60.42 & 48 & 100 & \\
\hline bleeding disorders & & 0 & 0.00 & 6 & 54.55 & 0 & 0.00 & 5 & 45.45 & 11 & 100 & \\
\hline $\begin{array}{c}\text { have you had since } \\
\text { graduation from } \\
\text { your academic } \\
\text { education }\end{array}$ & & & 0 & 2 & .00 & 0 & 0.00 & 2 & 50.00 & 4 & 100 & 0.095 \\
\hline When was the most & 0-6month ago & 0 & 0.00 & 10 & 55.56 & 0 & 0.00 & 8 & 44.44 & 18 & 100 & \\
\hline recent course you & a year ago & 0 & 0.00 & 5 & 38.46 & 0 & 0.00 & 8 & 61.54 & 13 & 100 & \\
\hline attended & $1-2$ years ago & 3 & 13.05 & 9 & 39.13 & 0 & 0.00 & 11 & 47.82 & 23 & 100 & 0.382 \\
\hline & $>$ 2years ago & 3 & 6.12 & 17 & 34.70 & 0 & 0.00 & 29 & 59.18 & 49 & 100 & \\
\hline Self-learning & No & 12 & 11.43 & 60 & 57.14 & 0 & 0.00 & 33 & 31.43 & 105 & 1001 & $0.020^{*}$ \\
\hline & Yes & 30 & 12.77 & 96 & 40.85 & 0 & 0.00 & 109 & 46.38 & 135 & 00 & \\
\hline
\end{tabular}

MCP: Mont Carlo exact probability

$* \mathrm{P}<0.05$ (significant) 
More than three quarters of the dentists (78.82\%) reported that they did not have enough undergraduate courses regarding bleeding disorders while the bulk of the remaining participants stated they got their knowledge from oral surgery (66.2\%) undergraduate courses. Only $30.29 \%$ have already attended continuing education courses mostly about $2-3$ courses $(46.60 \%)$ with the majority $(48.54 \%)$ stating that the courses attended were more than 2 years ago.

Data in Figure 1 show the categories of knowledge of the participating dentists regarding bleeding disorders and their management. Only 3.82\% had an excellent level of knowledge, $30.88 \%$ showed a good level of knowledge, more than one half (58.88\%) scored fair and finally, 6.47\% had a poor level of knowledge.

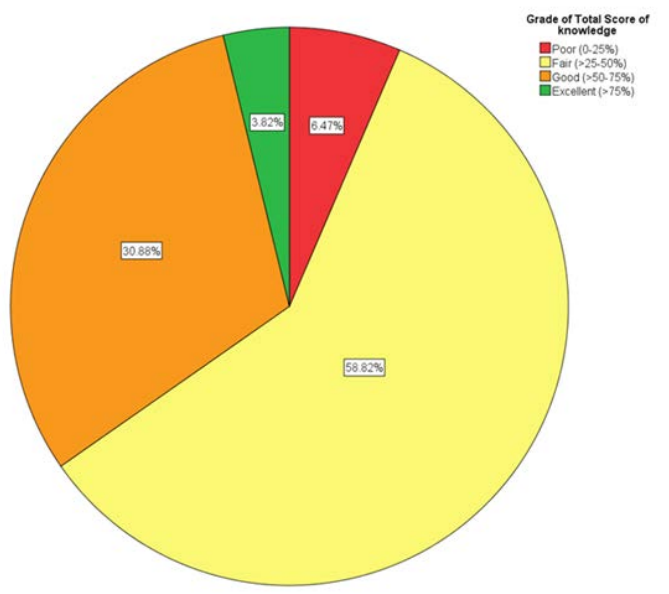

Figure (1): Categories of knowledge of the participating dentists regarding bleeding disorders and their management.

Figure 2 shows the categories of dentists' attitudes towards bleeding disorders and their management. Less than one quarter (22.35\%)of the respondents had an excellent attitudes towards bleeding disorders and their management while more than half (60.29\%) had a good attitudes. Those who had a fair attitudes were just $13.82 \%$ while only $3.53 \%$ had a poor attitudes.

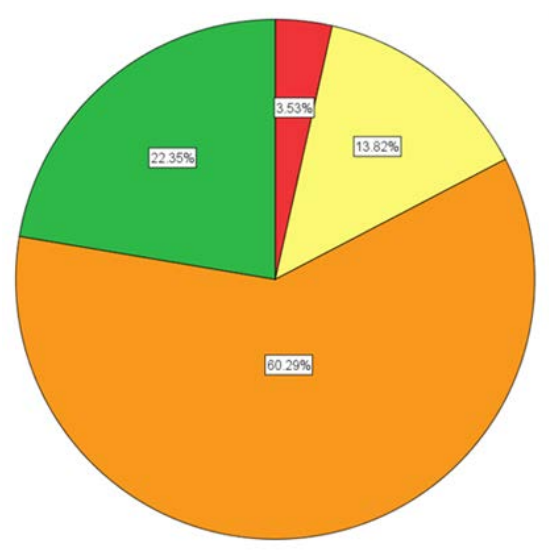

Figure (2): Categories of attitudes of the participating dentists regarding bleeding disorders and their management.

Categories of dentists' reported practices regarding bleeding disorders and their management are shown in Figure 3. Results showed that $41.76 \%$ of the dentists scored excellent for the reported practices regarding bleeding disorders, while $45.88 \%$ scored fair. Only $12.35 \%$ had a poor practice and none scored good.

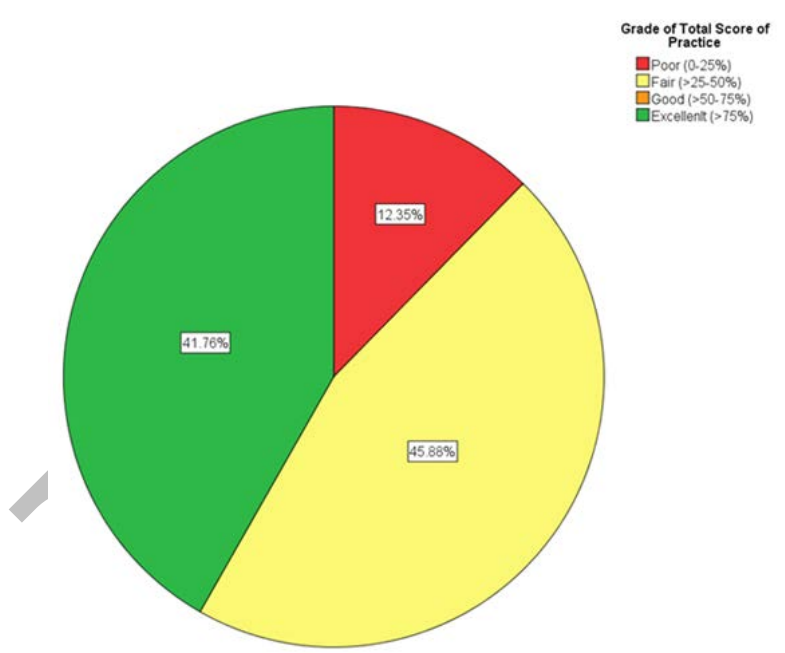

Figure (3): Categories of practice of the participating dentists regarding bleeding disorders and their management.

Regarding the relation between independent variables and knowledge, attitudes and reported practices scores, dentists aged 50 years and more were the most knowledgeable about bleeding disorders and their management, accounting for $7.69 \%$ whereas the lowest level of knowledge was found among dentists aged 30 to 40 years old $(7.85 \%)$, showing a statistically significant difference $(p=0.002)$.

Although no significant difference could be detected between general practitioners and specialists, the percentage of specialists with excellent knowledge scores $(4.20 \%)$ was higher than that of general practitioners (3.62\%). Furthermore, the most knowledgeable were oral surgeons $(9.68 \%)$ followed by public health dentists (8.69\%), with no statistically significant difference between both subgroups.

Dentists, who had post graduate training courses and self-learned, had slightly higher scores of knowledge (3.88\% and $3.83 \%$ respectively) compared to (3.80\% and $3.80 \%$ respectively) among those who did not have training courses or try to self-learn. This showed statistically no significant difference $(\mathrm{p}=0.225$ and $\mathrm{p}=0996$ respectively).

Participants aged 40 to 50 years old (25\%) and specialists (28.57\%) showed the topmost attitudes towards management of patients with bleeding disorders, with statistically significant difference where $p=0.010$ and $\mathrm{p}=0.031$, respectively. Regarding specialists, although oral surgeons were the most knowledgeable, they had the lowest attitudes (poor attitudes accounting for2.33\%) towards the disease, whereas prothodontist had the highest attitudes at $77.78 \%$ with no significant difference detected $(p=0.82)$.

Similarly, participants who had postgraduate training courses and tried self-learning had more positive attitudes (31.07\% compared to $18.57 \%)$ and (23.40\% compared to $20 \%)$, showing a statistically significant difference $(\mathrm{p}=$ 0.009 and $\mathrm{p}=0.043$ ) respectively.

Dentists aged 40 to 50 years old showed the best practice scores (53.57\%) compared to those aged 20 to 30 (29.47\%), with no statistically significant relation $(\mathrm{p}=0.124)$. 
Specialists (57.96\%) exhibited better practices compared to general practitioners (33.03\%), showing a statistically significant difference $(\mathrm{P}=0.000)$. Concerning specialists, pedodontists adopted the best practices (85.19\%) followed by public health specialists (73.91\%) $(\mathrm{P}=0.004)$.

\section{DISCUSSION}

In Egypt, no available data regarding the knowledge, attitudes and reported practices of dentists about management of patients with bleeding disorders could be secured. Considering the expected increase in prevalence of bleeding disorders in Egypt (16), the present study attempts to provide valuable baseline information, for better planning and implementation of oral health services for such less privileged subgroups of the population.

More than half of the sample (58.82\%) scored fair knowledge (Figure1). The present findings are not consistent with an Indian study (17), reporting that most of the dental students had good knowledge about management of patients with hemophilia. Again, Robati and Farokhi (18), reported that Iranian dentists' knowledge about bleeding and clotting disorders was at a moderate level, with no significant difference in the mean knowledge scores among males and females which is not in agreement with the present findings. The relatively low knowledge of the current study participants could be attributed to the fact that bleeding disorders and their management are not sufficiently included in the undergraduate curriculum.

More than half of the respondents had a good attitude regarding patients with bleeding disorders and their management. Similarly, in India, AbulHasan (17) found that the majority of the students showed positive attitudes towards learning about dental management of patients with bleeding disorders.

A little less than half the study sample scored excellent practice (Figure 3). Potdar et al (13) confirmed that appropriate knowledge on management of patients with bleeding disorders must be given so that dental students and post graduates would provide adequate treatment. The authors reported that additional special training should be provided to improve their skills in the management of such patients. KUMAR (19) reported that hesitation of dental students in following proper guidelines shows that the management of patients on antiplatelet therapy still needs more clarification. It was suggested that educational programs or workshops related to the subject were needed to increase the awareness of students to update their knowledge and practice related to managing patients on antiplatelet therapy before dental treatment.

Dentists aged 50 years or more and specialists had the highest level of knowledge regarding bleeding disorders and their management followed. This may be attributed to the longer years of experience dealing with such patients. The results of the current study regarding age was consistent with a study conducted by Gopalasamy (20) who reported that the knowledge level was significantly higher among dental post graduates due to their increased exposure to bleeding disorders cases and hence more experience in treating such patients.

The most favorable attitude towards bleeding disorders was also reported by participants aged $40-50$ years old. This might be because dentists in the $\mathrm{MOH}$, are subjected to training in many hospitals, which probably increases their chance to treat patients with different systemic diseases and different levels of the disease, thus positively affecting their attitude. Regarding specialists, prothodontists had the best attitude regarding bleeding disorders patients. This is probably because, prothodontists usually work with old aged patients most of the time which might predispose them to many comorbidities that need special attention and thus; provides them with sufficient background and positive attitude for the management of their patients.

The dentists aged 40-50 years old showed the best practice scores compared to younger 20 to 30 year old, which may be again due to the longer years of practice. Regarding specialty. Pedodontists showed the best practice scores compared to oral surgeons, which may be due to the stressful environment oral surgeons regularly work in which might be affecting their practice management.

Finally, the results from the current study showed that participants who attended postgraduate training courses and tried self-learning had the best knowledge, attitude and reported practice regarding patients with bleeding disorders and their management (Table 3A, B and C). Therefore, more workshops on bleeding disorders should be organized for the dental practitioners to keep them updated of the latest trends in management of those patients. This would help them to provide better services for patients with bleeding disorders and minimize the incidence of the potential emergencies associated with the dental treatment. Increasing the available resources of $\mathrm{MOH}$ facilities is also a vital step together with creating inter-professional learning experiences to enhance a multidisciplinary approach for bleeding disorders care.

\section{Limitations of the study}

Nevertheless, the current research had some limitations such as the large number of dentists who were on part time in many facilities, therefore the same facility was approached several times in order to compensate for the high number of absence during the first visit. However, remote districts like El Ameriyah and Borg El Arab were only approached once. There was some difficulty in approaching dentists due to their overloaded work and different schedules. Moreover, during conduction of the study, many of the surveyed dentists showed either negative attitude or indifference towards the research, which made it more difficult and time consuming.

\section{CONCLUSION}

More than half of the study participants had a fair level of knowledge, good attitude was represented by the majority of the participants and a little less than half had excellent practices.

\section{CONFLICT OF INTEREST}

The authors declare that they have no conflicts of interest.

\section{REFERENCES}

1-Gupta A, Epstein JB, Cabay RJ. Bleeding Disorders of Importance in Dental Care and Related Patient Management. Canad Dent Assoc J. 2007;73:77-83. Available from: URL: www.cda-adc.ca/jcda/vol-73/issue1/77.html

2-Meechan JG, Greenwood M. Part 9: Haematology and patients with bleeding problems. Br Dent J. 2003;195:30510. 
3-National Hemophilia Foundation. Bleeding disorders. New York; 2017. Available from: URL: https://www.hemophilia.org/Bleeding-Disorders/What-isa-Bleeding-Disorder

4-Patton LL. Bleeding and clotting disorders. In: Greenberg M, Glick M, Ship J editors. Burket's oral medicine: diagnosis and treatment, 11th ed. Hamilton Canada: BC Decker Inc; 2008. P. 411-34.

5-Blinder MA. Bleeding disorders. [Web site of the Washington University School of Medicine]. Available from

URL:

http://hematology.im.wustl.edu/conferences/presentations/ blinder080604.ppt

6-Potdar S, Ahmad E, Al-Johani K, Al Mushayt A, Reddy SG. Assessment of the Dental Students Awareness about Bleeding Disorders in Buraidah and Riyadh city, Saudi Arabia. Adv Hum Biol. 2016;6:7-11.

7-George A. Awareness of Bleeding Disorder among Dental Professionals. Int J Res Trends Innovation. 2017;2:24563315.

8-World Federation of Hemophilia. Report on the Annual Global Survey 2015. Montreal, Canada: WFH, 2015. Available at: URL: http://www1.wfh.org/publications/files/pdf-1627.pdf

9-Charan J, Biswas T. How to calculate sample size for different study designs in medical research? Indian J Psychol Med. 2013;35:121-6.

10-Little JW, Falace DA, Miller CS, Rhodus NL. Dental management of the medically compromised patient, 7th ed. St Louis: Mosby; 2003. P. 1-2.

11-Polit DF, Beck CT. The content validity index: are you sure you know what's being reported? Critique and recommendations. Res Nurs Health. 2006;29:489-97.
12-Snedecor GW, Cochran WG. Statistical Methods, 8th ed. Wiley; 1991.

13-Pearson K. On the criterion that a given system of deviations from the probable in thecase of a correlated system of variables is such that it can be reasonably supposed to have arisenfrom random sampling, The London, Edinburgh, and Dublin Philosophical Magazine andJournal of Science. 1900;50:157-75.

14-Benjamini Y, Hochberg Y. Controlling the false discovery rate: a practical and powerfulapproach to multiple testing. J R Soc Stat. 1995:289-300.

15-Waltz CF, Strickland OL, Lenz ER. Measurement in Nursing and Health Research, 3rded. Springer: 2005.

16-World Federation of Hemophilia. Report on the Annual Global Survey 2015. Montreal,Canada: WFH, 2015. Available at: URL: http://www1.wfh.org/publications/files/pdf-1627.pdf

17-Abul Hasan S, Kumar S.Knowledge and Awareness among Dental UndergraduateStudents Regarding Dental Management of Patients with Haemophilia. Int J Pharm Sci Rev Res.2017;44:27-31.

18-Robati27. Robati R, Farokhi M. Evaluation of the dentists' knowledge of inherited bleedingdisorders and anticoagulants in Shiraz, Iran. Ped HematolOncol. 2013;3:159-63.

19-Kumar S.Knowledge, Attitude and Practices of Dental Students toward DentalManagement of Patients on Antiplatelet Therapy. Asian J Pharm Clin Res. 2016;9:2706.

20-Gopalasamy K. Awareness among Final Year and Postgraduate Dental Students on Bleeding Disorders': A Questionnaire Based Study. Int J 